\title{
Make My Memory: How Advertising Can Change Our Memories of the Past
}

\author{
Kathryn A. Braun \\ Harvard Business School \\ Rhiannon Ellis \\ University of Pittsburgh \\ Elizabeth F. Loftus \\ University of Washington
}

\begin{abstract}
Marketers use autobiographical advertising as a means to create nostalgia for their products. This research explores whether such referencing can cause people to believe that they had experiences as children that are mentioned in the ads. In Experiment 1, participants viewed an ad for Disney that suggested that they shook hands with Mickey Mouse as a child. Relative to controls, the ad increased their confidence that they personally had shaken hands with Mickey as a child at a Disney resort. The increased confidence could be due to a revival of a true memory or the creation of a new, false one. In Experiment 2, participants viewed an ad for Disney that suggested that they shook hands with an impossible character (e.g., Bugs Bunny). Again, relative to controls, the ad increased confidence that they personally had shaken hands with the impossible character as a child at a Disney resort. The increased confidence is consistent with the notion that autobiographical referencing can lead to the creation of false or distorted memory. (c) 2002 John Wiley $\&$ Sons, Inc.
\end{abstract}


Advertisers play off consumers' memories and emotions through the use of autobiographical referencing. The use of such referencing can cause consumers to focus less on rational product information and more on the feelings evoked by their recollected memories (Sujan, Bettman, \& Baumgartner, 1993). Increasingly, marketers are using this technique to appeal to Baby Boomers where these past images represent lasting expressions of freedom and youth (Marconi, 1996). For example, Walt Disney celebrated the 25th anniversary of Disney World in Orlando with an advertising campaign entitled "Remember the Magic." The ads resembled vintage home movies and featured scenes of people swimming, meeting Mickey Mouse, and enjoying themselves on the theme park's exciting rides. The campaign's aim may have been to remind consumers of their own past happy childhood memories of the park in order to get them to revisit.

But what if such referencing could change what consumers remember about their childhood memories of visiting the park? Not all consumers have had happy experiences at Disney nor do they all have the ability to accurately conjure up those childhood images at will. Because consumers may use the advertising as a cue to recollect their past experience, there is the possibility that these recently generated advertising images may alter what consumers ultimately remember about their own childhood. After all, there is evidence that cues that get people to think over and over again about manufactured childhood events can be a relatively easy way to create false memories or beliefs about childhood (Loftus, 1997). Such findings have raised concerns about the accuracy of memories surfaced in hypnosis, guided imagery, or other prompts in psychotherapy (Lindsay \& Read, 1994; Loftus \& Ketcham, 1994).

Marketers have found that autobiographical memories may be spontaneously activated within the context of an advertising message (Baumgartner, Sujan, \& Bettman, 1992; Krugman, 1967). Marketers have further shown that they can increase the likelihood consumers will activate their memories by focusing on experiential information (Wells, 1986) or using dramatic narratives in their advertising campaigns (Boller, 1990). Autobiographical ads may cause consumers to imagine themselves in the advertised event, and this vicarious experience may alter how consumers remember their own past.

What if Disney's "Remember the Magic" campaign implanted memories into consumers of things that never happened? The possibility that marketing stimuli can direct, guide, or change consumers' autobiographical memories has gone largely untested. This research investigates whether the use of autobiographical referencing can cause imaginings of experiences (even impossible ones) that lead consumers to become more confident that certain events had happened to them as children. This possibility holds both managerial opportunities and ethical ramifications. 


\section{Autobiographical Memory}

Autobiographical memory can be defined as memory of past personal experiences. There has been much attention toward finding ways of accessing this type of knowledge because it is an important foundation of one's self-concept (Hyman, Husband, \& Billings, 1994). Sigmund Freud, for instance, believed his patients had repressed traumatic childhood memories in their subconscious and believed it was necessary to understand his patients' original childhood experiences in order to understand their adult problems.

Psychoanalysts believe childhood is important for understanding relationships because this is when attachment occurs, and those early relationships are thought to be prototypical of later relationships (Ainsworth, 1985). As applied to the consumer setting, early childhood brand relationships may set the emotional stage for later adult brand relationships. Consumers' memories of brands or brand experiences from childhood thus may have a great consequence in their decision making, as they conjure up those past emotional attachments: "These trails of autobiographical memories - they are perceived as veridical records accompanied by strong visual and, hence, vivid reliving of the original experience-are not only important in themselves, but especially because they suggest that the original emotions are also likely to be important components of autobiographical memories" (Baumgartner et al., 1992 , p. 55, italics added).

Both psychoanalysts and marketers use cues to prod people to remember their past. In his work Freud eventually came to the conclusion that his patients were fantasizing much of their childhood experiences based on his own suggestions. The marketing-research paradigms have focused on how brands might associate themselves with actual past consumer experiences. Virtually no research has examined memories of brand experiences, in particular childhood ones, and the manner in which the advertising influences those recollections. In light of previous findings on autobiographical referencing an important and yet unexplored question arises: Might exposure to an autobiographical ad alter consumer's recollection of a past childhood experience or even create a memory of an experience that never happened? For instance, some childhood memories may be based more on recurring ads consumers are exposed to rather than on recollection of actual childhood events. Similarly, some consumers may come to believe that they had taken part in an experience when in fact they had only viewed an ad of the event.

This alteration is possible because of the reconstructive nature of memory (see Schacter, 1995 for a full review; Braun, 1999, for its application in marketing). A consumer's past is constantly being updated to fit one's changing self-knowledge and social contexts (Bruner, 1986; Neisser \& Fivush, 1994; Spence, 1982). The process of rewriting one's history is natural and allows one to adapt to possibilities in the future 
(Hyman \& Pentland, 1996). As time passes there lies a greater likelihood that temporally available information will be used to reconstruct, and perhaps distort, how the experience is remembered (Thompson, Skowronski, Larsen, \& Betz, 1996).

\section{False Memories and Imagination Inflation}

Memories that have had time to fade are particularly subject to distortion. For example, Loftus and Pickrell (1995) suggested to adult participants that at age five they had been lost in a shopping mall and rescued by an elderly person. About a quarter of the adults fell sway to this suggestion. Using a similar procedure, Hyman and Pentland (1996) suggested and had participants imagine having spilled a bowl of punch at a wedding as a child. About a quarter of adults fell sway to this suggestion, and even more did so when imagination of the experience was encouraged. The false memories typically incorporated the punch-bowl incident into a broader account based on accurate personal knowledge. These studies show that with suggestion and imagination a significant minority of people can be led to believe that they had experiences that were manufactured, and many of them elaborated upon those false experiences with idiosyncratically produced details.

The act of imagining oneself having a childhood experience forces people to create alternatives to reality (if the experience never happened; Roese, 2000 discusses other effects of counterfactual thinking). The ease with which these vividly pictured figments of the imagination come to mind may promote their acceptance as real regardless of their actual veridicality (Schwarz, 1996). Such imagining might induce source attribution errors whereby the recently imagined event becomes confused with the actual past. Researchers find it is particularly difficult to detect differences between recent imaging and childhood memory. For instance, Johnson, Foley, Suengas, and Payne (1988) asked participants to think of actual or imagined personal events from either the recent past or childhood and then rate them on a number of characteristics. They found far fewer significant differences between actual and imagined childhood events than for actual and imagined recent events.

A common result of having people imagine an experience is increased confidence that the event occurred. Garry, Manning, Loftus, and Sherman (1996) looked at the relationship between cues asking participants to imagine an experience and the later reporting of the event happening to them as a child. In their paradigm they asked participants to rate the likelihood certain childhood events happened to them on a lifeevents inventory (LEI) containing many experiences, for example, getting lost in a shopping mall. Two weeks later, half of the participants were instructed to imagine themselves as children experiencing several of these events, including some that had never happened to them. Only 
participants who performed the imaginative exercise reported substantial rises in confidence that both actual and illusory incidents had occurred. The researchers called this effect imagination inflation.

\section{Experimental Investigation}

Although there is empirical evidence that suggestions can influence childhood memory, a question arises as to whether it is possible for a marketer to exert an influence with suggestions in the form of advertising. The first study investigates whether autobiographical advertising can prompt consumers to image their childhood experiences so their memories become more consistent with the images evoked in the advertising. That first study focuses on a central childhood experience, visiting Disney World, and specifically shaking hands with Mickey Mouse. It is known from past research that pictures or images can trigger stronger remembering (Schacter, Johnson, Angell, \& Gross, 1997), and that actions can be of superior value for prompting reconstruction because they typically form the unique attribute of a specific event (Anderson \& Conway, 1993). Further, it is known that when people recount their past experiences they begin by visualizing perceptual details and embellish their memories based upon those details (Belli \& Loftus, 1996). For that reason, the target ad incorporated various images from the park - from Disney's glistening castle to the mention of the theme song from "It's a Small World." The ad began with "Remember the Magic" and describes a day in the park from a child's perspective, with the culmination being shaking hands with Mickey Mouse. (See Figure 1).

It is predicted that if the ad is part of the reconstruction process, the ad elements or images may be likely to appear as part of consumers' reconstructed memory of their visit, regardless of whether or not the events had actually happened. In addition, if the ad causes imaging of the childhood experience, then this imagination process will lead consumers to believe the ad-based experience of shaking hands with Mickey happened to them as a child-advertising inflation.

\section{EXPERIMENT 1}

The purpose of this study was to determine whether autobiographically focused advertising could directly affect how consumers remember a prior childhood experience. This is important for marketers because, although it is known that past experiences can be an important driver in future purchase, it is not known whether marketers can evoke or alter memories of childhood experiences through their advertising messages. 


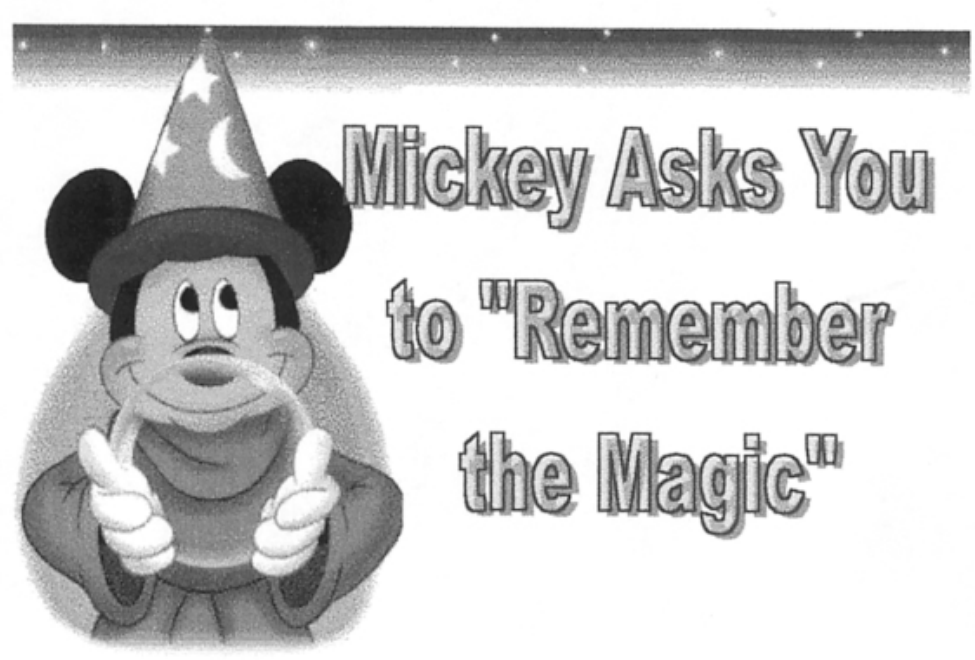

Go back to your childhood....and remember the characters of your youth, Mickey, Goofy, and Daffy Duck...Try to recall the day your parents finally brought you to their "home" at Walt Disney World® resort... Imagine how you felt when you first saw Mickey with your own eyes up close... Your mother pushing you in his direction so you would shake his hand, wanting to capture the moment in a picture. You needed no urging, but somehow the closer you got, the bigger he got... He doesn't look that big on TV, you thought. And a moment before reaching him you stop in your tracks. It hits you. And it hits you hard. Mickey, the character you've idolized on TV, is only several feet away. Your heart stops but that doesn't stop your hands from sweating. You wipe them off just before reaching up to grab his hand. The excitement rushes through you, you don't know whether you'll faint or explode. And then the moment is over, the only remnants being your flush face and a soon-to-be developed picture.

Moments such as these are lived every day at Walt Disney World® resort. All children get the chance to meet their favorite characters up-close. It's a memory we all share and hold dear as part of our childhood.

But the happy memories don't have to end there... The most memorable, most magical Walt Disney World® celebration ever is under way now! It's a spectacular "thank you" to everyone who has made our first 25 years so special. This once-in-a-lifetime celebration is filled with wonderful new shows and attractions, grand openings, and non-stop festivities everywhere you look! Relive your favorite Disney memories and create everlasting new ones anytime between now and January 31,1998 !

\section{It's Time to Remember the Magic!}

Figure 1. Autobiographical ad. 


\section{Method}

Subjects. The participants were 107 undergraduates (64 female, 43 male) from a Midwestern university who received course credit for their involvement.

Design. A single-factor between-subjects design was used. Half the participants received the Disney ad, the other half received a control, nonDisney ad. The participants were randomly assigned to one of these conditions. Random assignment left 46 in the Disney ad condition, 51 in the control condition.

Materials Procedure. The experimental procedure was adapted from the Garry et al. (1996) imagination inflation paradigm. On the first week participants were given a list of 20 childhood events and asked to indicate whether or not the events had happened to them under the age of 10 . They rated these on a $100-\mathrm{mm}$ line where $0=$ definitely did not happen, 100 = definitely did happen. The target item was "Met and shook hands with a favorite TV character at a theme resort." This item appeared fourth on the list. The LEI survey was given within several other experimental tasks. They were asked to come back the following week to finish one of those experiments.

The following week half were given the Disney ad, the other half the control ad, by another experimenter. They were encouraged to imagine themselves experiencing the situation appearing in the ad, and were given 5 minutes to write down how the ad made them feel and what it made them think about. Afterwards, participants rated the ad on four bipolar attitude scales anchored by: "unfavorable,"-"favorable," "badgood," "unpleasant-pleasant," and "negative-positive" on a 100-mm line, where a higher score indicates more favorable attitudes. They rated how involving the ad was for them, with the use of empathy measures adapted from the Wells $R$ scale (1986): "I felt I was right there in the ad experiencing the situation again," "I really got involved in the feelings provoked by the ad," "While I was looking at the ad, I could easily put myself in the situation," and "While looking at the ad, I felt that the events were happening to me." These measures were anchored from $0=$ "strongly disagree" to $100=$ "strongly agree."

After a 5-minute distraction task, the original experimenter from Week 1 came in, appearing to be rather panicked, and said there had been a problem with coding the autobiographical data and could they please fill out the life-events inventory again.

After a 15-minute distraction task, participants were asked about their memories of Disney in a questionnaire delivered by a third experimenter. Participants were asked directly if they had ever visited Disney before they were 10 and if so, to describe their memory of that event. They were asked how well they remembered the event $(1=$ "not at all," 
7 = "perfectly") whether the memory was pleasant (where $-3=$ "extremely unpleasant," 3 = "extremely pleasant"), the emotional involvement in the experience ( 1 = "nothing," 5 = "extreme"), centrality to their childhood ( $1=$ "not central," 3 = "central"), and personal importance to their childhood ( $0=$ "trivial," $100=$ "very important"). These scales were adapted from Thompson et al. (1996). Last, as a means to assess demand characteristics, participants were asked what they thought the purpose of the experiment was, and whether or not they believed their memories of Disney had been influenced by the advertising.

\section{Results}

Coding Procedure. Two independent judges coded participants' reactions to the ads and the recall statements of their Disney experience. They had no knowledge of the experimental hypotheses. Their interrater reliability was 0.83 and an average was used for the analysis.

Autobiographical Effects of the Advertising. The judges looked at participants' written protocols to determine whether there was mention of a past experience, a report that the ad caused the participant to imagine or evoke his or her experience, or mention of future expectations regarding the resort. Out of the 46 participants who received the autobiographical ad, 30 (or 65\%) mentioned memories of Disney World, 34 (or 74\%) mentioned that the ad caused them to imagine the experience, and 29 (or 63\%) mentioned future visits to the park. For instance, one participant wrote:

It made me think back to when I was a kid and went to Disney World. It was great. I remembered eating all day long, riding on Space Mountain for the first time, and especially meeting Mickey Mouse! It made me want to beg my parents to go there over Christmas break. I want to re-live the memories I had as a child.

As Baumgartner et al. (1992) found, this reliving can cause nostalgic feelings:

I felt very nostalgic, remembering what it was like the first time I was at Disney World. Disney World seems like a fantasyland "dreamlike" place to visit. A magical place where memories take place.

Even those who had not visited the park in the past were able to generate this imagination process: "It made me want to visit Disney World even more than I already want to. It describes it just like I imagine it to be."

Imagination Inflation. To reiterate, a major goal of Experiment 1 was to access whether exposure (plus imagination) to an advertisement 
about a product can increase participants' confidence that certain events occurred in their own past childhood experience with that product. The first analysis explored whether participants became more confident that the critical event occurred by examining whether LEI scores moved up or down, for the critical item "shaking hands with a TV character at a theme resort." The difference between Week 2 and Week 1 was the dependent measure - a score of 0 would indicate no memory change, a positive score a memory inflation, and a negative score a memory deflation.

Because the interest was in seeing if the ad could make the event more probable, people who were (at Week 1) quite certain that they had already experienced the shaking-hands event were eliminated from the data set. That left those who reported the shaking-hands incident had a low likelihood of occurrence on the first LEI, defined as a $0-50$ on the line mark scale, to determine if the ad increased their confidence the event had occurred (as per Garry et al., 1996), which left 73 participants (32 control, 41 Disney). There are several ways to analyze this data. The first analysis looked at the number of people in each group that showed an increase, decrease, or same report on the LEI (see Figure 2). Significantly more people who received the Disney ad went up on the LEI, $90 \%$ versus $47 \%$ in the control, significantly different at $\chi^{2}(2, N=73)$ $=17.3, p<.0001$. In addition, mean difference scores on the LEI were analyzed. A positive difference would indicate greater confidence the event had happened to them, a negative difference less confidence. The Disney group showed a more positive change, $M=37.05$, than the

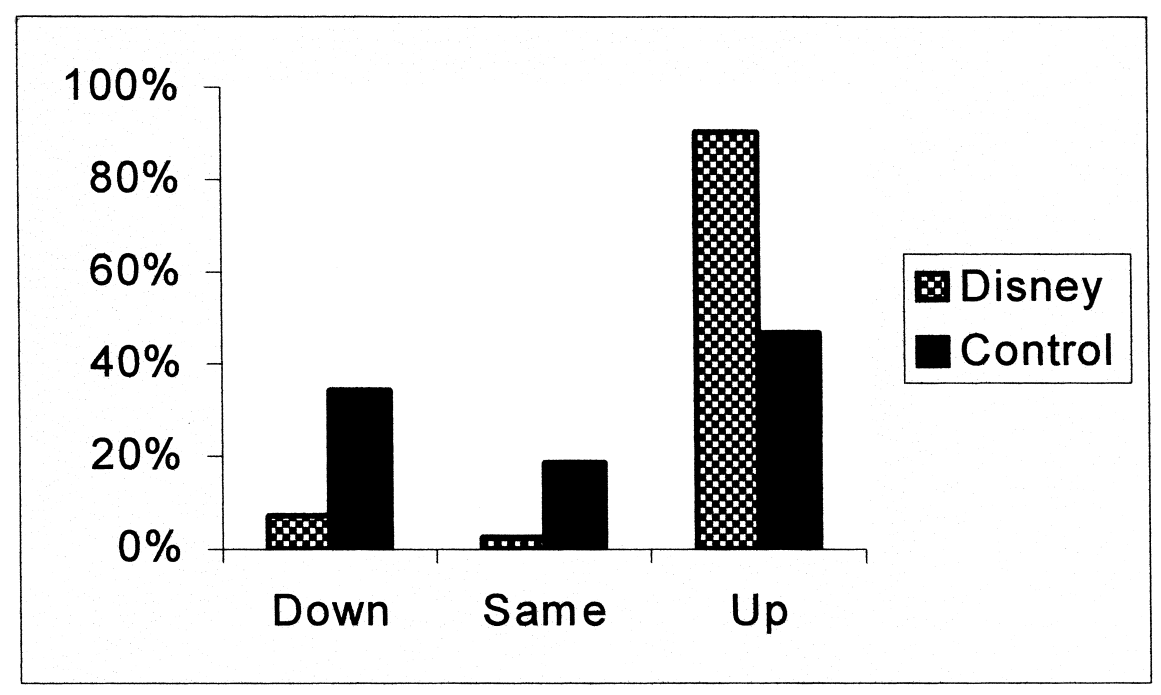

Figure 2. Experiment 1: Change in LEI "shaking hands." 
control group, $M=-1.5$ significantly different at $t(71)=5.93, p<$ .0001. There were no significant differences on the other 18 items on the LEI test.

Another question of interest is which (if any) advertising measures would best predict the advertising/imagination inflation. Earlier work by Krugman (1967) suggests that autobiographical referencing may increase involvement, and Wells (1986) argues that traditional attitudetoward-ad measures may not effectively capture this effect. The four traditional ad-rating measures, where participants indicated their overall liking for the ad, loaded on one factor with coefficient alpha $=.92$ and were combined into an ad attitude/rating index. The Wells $R$ involvement with ad measures, where participants indicated how emotionally involved they became in the ad-based situation, also loaded on one factor with coefficient of 0.90 and were combined to form an involvement index. Here it was found that the correlation between the ad attitude index and the LEI memory change was $r=.08$ and involvement in ad measures was $r=.31$, showing that in absence of the LEI change data, the Wells scale can capture the memory effects slightly better than traditional ad-attitude measures can.

Disney Memory. Thirty-four participants from the Disney ad group and 34 from the control group reported having visited a Disney park in the past. They were asked to describe and rate that visit on several scales. The two judges coded the recall statements on the number of words, independent thoughts, positive thoughts, negative thoughts, and elements from the ad that were mentioned. For the latter, the judges looked at the recall statements for usage of words from the ad (e.g., "magical") and actions from the ads (e.g. "cool rides" or hearing "It's a Small World"). One participant, who appeared to be heavily influenced by the advertising, wrote:

Went on lots of different rides, met Mickey Mouse, watched the "Small World" show . . . hug . . . Got sick from too much junk food, got drenched on log ride. . .

The ad had featured meeting Mickey Mouse, the "It's A Small World" song, and a variety of rides and food. That response would have scored a 4 on elements. Because some of these ad-suggested ideas may naturally appear in one's recall of Disney, the autobiographical ad condition was compared to the control condition to assess whether the ad increased their appearance. There were no significant differences in the length or number of thoughts between the Disney/control condition; $M=31$ words in the Disney condition, $M=26$ in the control condition; $M=4.4$ thoughts in the Disney condition, $M=4.1$ in the control condition. There were significantly more positive thoughts $(M=3.6)$ in the Disney ad condition than in the control $(M=2.8, t[66]=2.07, p=.02)$. 
There were no differences in negative thoughts; $M=0.79$ in Disney, $M=0.50$ in control, $t<1$. There were more ad elements appearing in the recall in the ad condition $(M=2.38)$ than in the control $(M=1.47$, $t[66]=2.65, p=.005$ ).

Participants also rated their memory on several objective measures; means appear in Table 1. Those who received the Disney ad rated their memories as being more personally important, $t(66)=1.93, p=.025$; better remembered, $t(66)=3.11, p=.001$; more pleasant, $t(66)=2.17$, $p=.015$; and more central to their childhood, $t(66)=1.59, p=.055$ than those who did not receive the Disney ad. There were no significant differences in emotive aspects of recall, $t<1$.

Demand. Participants were asked to guess the purpose of the experiments in order to assess demand factors. No one correctly responded that the advertising was intended to alter their childhood memories. Additionally, participants were asked whether the advertising helped them remember anything from their own experience that they might

Table 1. Objective Memory Measures

\begin{tabular}{|c|c|c|c|}
\hline & \multicolumn{3}{|c|}{ Experiment 1} \\
\hline & Disney & Control & \\
\hline $\begin{array}{l}\text { Personal importance }(0=\text { trivial }, \\
100=\text { very important })\end{array}$ & 64 & 51 & \\
\hline $\begin{array}{l}\text { How well remembered }(1=\text { not } \\
\text { at all, } 7=\text { perfectly })\end{array}$ & 4.8 & 3.9 & \\
\hline $\begin{array}{l}\text { Pleasantness of visit }(-3=\mathrm{ex}- \\
\text { tremely unpleasant, } 3=\mathrm{ex}- \\
\text { tremely pleasant) }\end{array}$ & 2.4 & 2.0 & \\
\hline $\begin{array}{l}\text { Centrality to childhood }(1=\text { not } \\
\text { central, } 3=\text { central })\end{array}$ & 2.2 & 1.7 & \\
\hline \multirow{3}{*}{$\begin{array}{l}\text { Emotional involvement }(1= \\
\text { nothing, } 5=\text { extreme })\end{array}$} & 3.6 & 3.5 & \\
\hline & \multicolumn{3}{|c|}{ Experiment 2} \\
\hline & Ariel & Bugs & Nonautobiographical \\
\hline $\begin{array}{l}\text { Personal importance }(0=\text { trivial }, \\
10=\text { very important })\end{array}$ & 5.6 & 5.5 & 5.0 \\
\hline $\begin{array}{l}\text { How well remembered }(1=\text { not } \\
\text { at all, } 7=\text { perfectly })\end{array}$ & 4.4 & 4.3 & 3.9 \\
\hline $\begin{array}{l}\text { Pleasantness of visit }(-3=\mathrm{ex}- \\
\text { tremely unpleasant, } 3=\mathrm{ex}- \\
\text { tremely pleasant) }\end{array}$ & 2.1 & 2.4 & 2.1 \\
\hline $\begin{array}{l}\text { Centrality to childhood }(1=\text { not } \\
\text { central, } 3=\text { central })\end{array}$ & 2.3 & 2.2 & 1.8 \\
\hline $\begin{array}{l}\text { Emotional involvement }(1= \\
\text { nothing, } 5=\text { extreme })\end{array}$ & 3.8 & 3.8 & 3.5 \\
\hline
\end{tabular}


not otherwise have been able to remember. Forty-one participants who received the Disney ad said "no"; 5 said "yes." They were also asked if the ad they saw for Disney made them remember their experience to be different than it really was. For instance, did the ad make them remember having a positive experience when in fact it was very negative? Forty-three participants said "no," and only 3 said "yes."

\section{Discussion}

The purpose of this study was to determine whether an autobiographical ad could make consumers more confident that they had experienced an advertised-suggested event as a child. It was found that autobiographical advertising can indeed induce this effect. The participants became more confident that they had shaken hands with a TV character after viewing the advertising than if they had not received that retrieval cue.

Figure 3 depicts three routes that could be happening as participants recalled the shaking-hands event, adapted from Haber and Haber (1996). Route 1 represents those who rated the shaking-hands experience high on both the LEI pre- and posttests; in other words, they did not need the ad to retrieve that memory, and those people were not included in the LEI analysis for that reason. Routes 2 and 3 are the most interesting with respect to the role autobiographical advertising has on cuing past experiences, for both routes represent those individuals that increased on the LEI test after receiving the Disney ad. The paradox of offering a retrieval cue is that it can help access both true and false memories (Spiegel, 1997). As Garry et al. (1996) note in their study of imagination inflation, some of the observed increases could be due to the ad providing an effective cue in surfacing a veridical memory. In other words, perhaps some participants at Week 1 forgot about shaking hands with Mickey and the ad helped surface that encounter. However, it is possible that the ad may have implanted that experience in consumers' minds.

It was impossible to determine whether in fact participants had ever shaken hands with Mickey Mouse, and thus is not clear whether Routes 2 or 3 were occurring. One way to determine this would be to get participants to remember an event that would have been impossible, for example, getting them to remember shaking hands with a character who became popular later, but did not exist at the time the participant would have been to a Disney park or, alternatively, feature a competitor's character (e.g., Warner Bros. Bugs Bunny), who would have never been in the park. If advertising leads people to claim an impossible experience, there would be evidence for the creation of false memories. This reasoning guided the design of Experiment 2. 


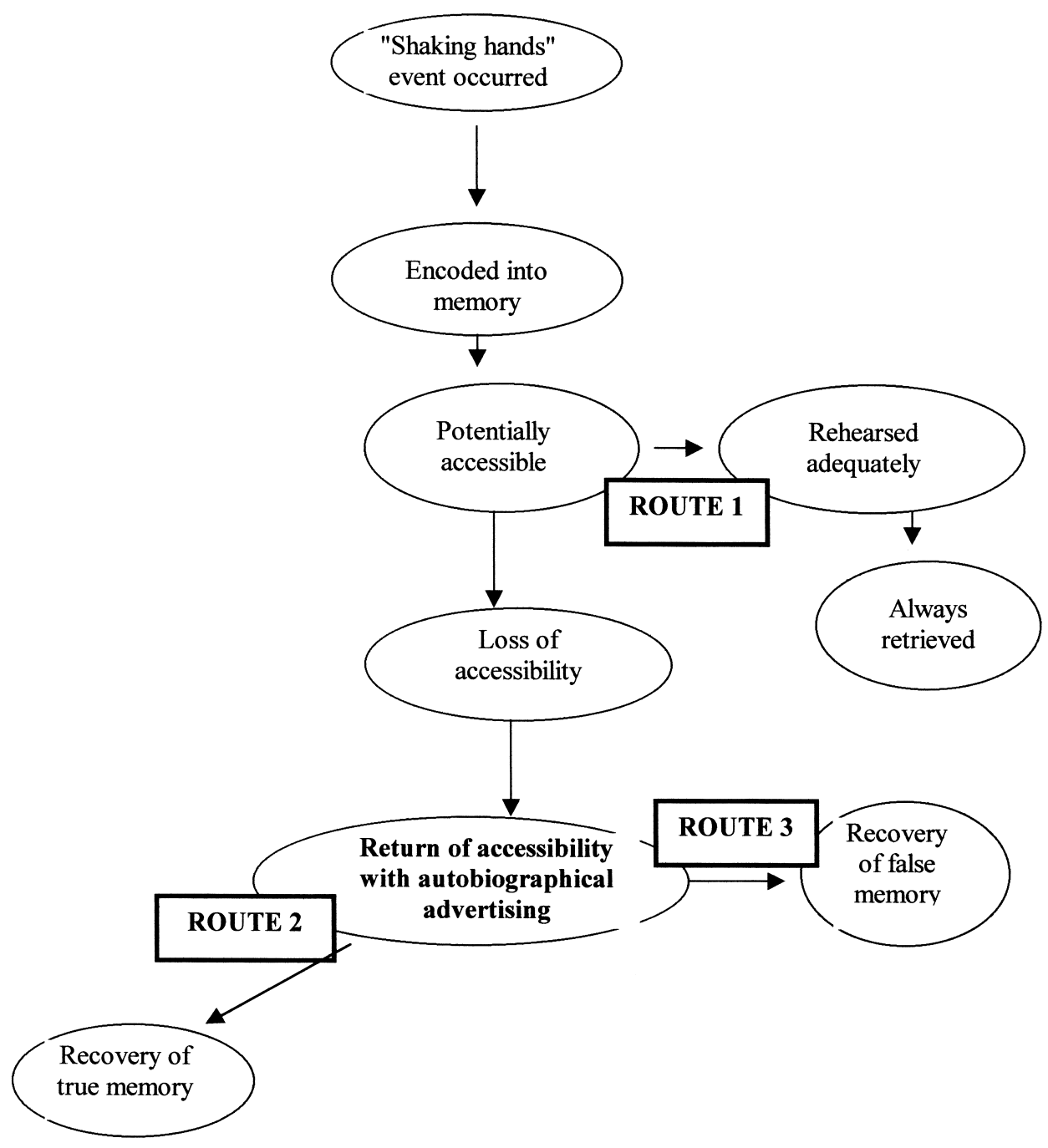

Figure 3. Routes to memory retrieval.

\section{EXPERIMENT 2}

The purpose of this experiment was to determine whether false information in advertising about childhood experiences at Disney could make consumers believe those events had happened to them. Two types of false information were tested within the same ad format as used in Experiment 1: In one ad it was suggested that they had shaken hands with Bugs Bunny (a Warner Bros. character); in another ad it was suggested they had shaken hands with Ariel, the Little Mermaid (a Disney character not yet introduced at the critical childhood time period, before the age of 10). Bugs, meanwhile, was around during participants' child- 
hood but would have never have been at a Disney resort. A nonautobiographical Disney ad served as a control group in order to investigate whether it is the autobiographical nature of the ad that is influencing consumers' past or the mere Disney mention that is triggering the results. ${ }^{1}$ The nonautobiographical ad was more informational in nature (Puto \& Wells, 1983), focusing on a new ride being offered at the park and providing information about how to order park tickets via the Web at a discount price.

\section{Method}

Subjects. The participants were 167 (104 female, 63 male) psychology undergraduates at a western university who received credit for their involvement. ${ }^{2}$

Materials and Procedure. The same basic procedure from Experiment 1 was followed, with some adaptations. Participants took the first LEI during a mass-testing situation and indicated whether or not they would be interested in participating in an upcoming ad study. Those who said "yes" were contacted and were assigned to one of the three ad conditions. Some screening occurred: Those who had visited Six Flags were eliminated to reduce a possible source-confusion error (Bugs Bunny does make an appearance at that park).

The target LEI measure was modified to "shaking hands with a cartoon character in a theme park" with a 10-point scale anchored by "definitely did not happen"/“definitely did happen." The Disney World focus was changed to Disneyland because of the higher likelihood that the students would have visited that California resort. All dependent measures were converted to numbered scales instead of the 100-mm line marks used in Experiment 1. The discrete numbering system simplified analysis.

The advertising measures were also the same as Experiment 1, but were measured on an 8-point scale, with higher values indicating greater liking or involvement. A few measures were added to determine whether in fact the false information had become a part of participants' childhood memories. The participants were asked to indicate with what confidence they had seen some characters at the park (with Bugs and Ariel being the target items buried within a set of other characters) and then to specifically remember what characters they had actually shaken hands with (again Bugs and Ariel were buried within a list). Specifically,

${ }^{1}$ The researchers felt it was important to have all groups imagine the Disney experience to see what effect the autobiographical referencing had by just mentioning the Disney name, as other researchers have found spontaneous activation of autobiographical memories in the presence of advertising (Baumgartner et al., 1992).

${ }^{2}$ Differences in cell sizes in reported tests result from some participants skipping over measures. This did not occur frequently nor in an uneven distribution across conditions. 
they were asked to indicate their confidence that they had met the following characters, with Bugs appearing third and Ariel appearing fifth on a list of eight characters, and to put an "X" in front of characters they had actually met in person (e.g., shaking their hand); the Bugs and Ariel placement was the same on this list of eight characters.

\section{Results}

Autobiographical Effects of Advertising. The two autobiographical ads were more involving for participants, scoring higher than the nonautobiographical Disney ad on the Wells $R$ scale index, formed as in Experiment 1 except that the scale now ranged from 1 to 8, with lower scores indicating less involvement. Means follow: 5.2 for the Ariel, 5.1 for the Bugs, 3.8 for the nonautobiographical Disney ad; a $t$-test comparison showed the two autobiographical ads were significantly higher than the nonautobiographical ad, $t(165)=4.3, p<.0001 .^{3}$

The ad attitude/rating index showed no significant difference across the groups; the new range for attitude scale was 1 to 8 , with lower values indicating less-favorable attitudes. Means follow: $M=5.9$ Ariel, $M=$ $5.8 \mathrm{Bugs}, M=5.5$ nonautobiographical Disney, $F<1$. Therefore, the Wells index can better differentiate types of advertising that influence memories than traditional ad-attitude measures.

Imagination Inflation. Recall that participants indicated how likely the target event, shaking hands with a cartoon character at a theme park, happened to them before the age of 10, on a 10-point scale, where 1 = "definitely did not happen" and 10 = "definitely did happen." They filled out the life-events inventory twice, once during the mass testing, and then again in a subsequent session. The discrete numbering scale allowed for a more precise segmentation than Experiment 1. Those who had indicated the event was unlikely to have happened to them (scoring $1-5$ on the initial test) were eliminated, which left 106 participants (34 Ariel, 36 Bugs, 34 nonautobiographical ad condition). The interest was in determining if those individuals who had rated the event as being relatively unlikely would increase their confidence it had happened to them after seeing the false autobiographical suggestions in the advertising. Figure 4 depicts those individuals from each group and the direction of movement on the target LEI item, "shaking hands." All groups showed a tendency to increase but it was more pronounced in the con-

\footnotetext{
${ }^{3}$ Because the interest was in the difference between autobiographical and nonautobiographical advertising effects, the two autobiographical groups were combined after finding no significant difference between them in order to assess if they were different from the other type of ad. Another way to analyze this would be to run an ANOVA on the three groups and do post-hoc comparisons. This was done as well, with similar results. For simplicity, only the $t$-test results are reported. In these $t$ tests pooled variance was used, and when directionality was predicted, one-tailed $p$ values were reported. This technique was used throughout Experiment 2.
} 


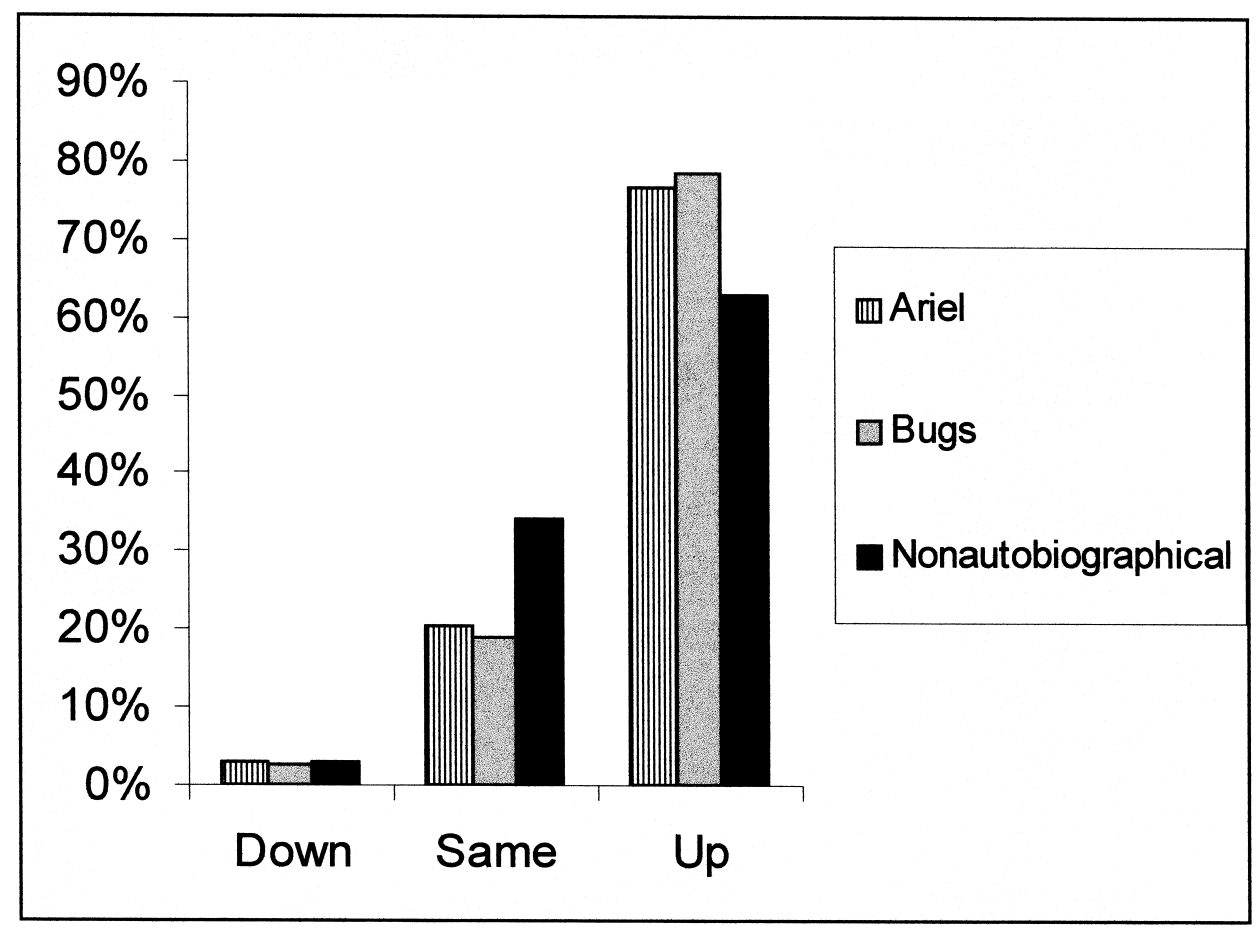

Figure 4. Experiment 2: Change in LEI "shaking hands."

ditions that received an autobiographical ad-76\% in the Ariel condition, $78 \%$ in Bugs, and $62 \%$ in the nonautobiographical condition - the autobiographical groups being significantly more likely at $\chi^{2}(1, N=106)$ $=2.5, p=.05$. Mean movement on the LEI was also compared across groups, $M=4.8$ for Ariel, 5.1 for Bugs, 3.8 for nonautobiographical Disney. Participants in the autobiographical ad conditions displayed significantly greater movement in their confidence that they had shaken hands than their nonautobiographical counterparts; $t(104)=1.95$, $p=.05$.

As found in Experiment 1, the Wells $R$ scale was more correlated with the change in LEI than the ad attitude scale, $r=0.2$ Wells, $r=-.1 \mathrm{ad}$ attitude.

Disney Memory. All participants were asked to write about and rate their memory of their childhood experience at Disney; 46 in the Ariel condition, 56 in the Bugs condition, and 46 in the nonautobiographical condition did so. Those that received the autobiographical ads reported better clarity in their memories, $t(109)=2.07, p=.02$; more emotional content, $t(111)=1.64, p=.05$; more centrality of memory to childhood, $t(121)=2.26, p=.01$; and more importance to their childhood, $t(110)$ $=1.76, p=.04$. There was no significant difference on pleasurable memories between conditions. Means appear in the bottom of Table 1 . 
False Memory. Participants were asked more directly about specific images (false ones) that may have happened on their childhood visit to the park. The interest was whether they would report greater confidence in having met or remembering shaking hands with either Ariel or Bugs if they received those respective ads. They were first asked to indicate confidence that they had met several characters at the park on a scale of 1 to 7, anchored by "not very confident" and "very confident." Confidence in meeting Bugs was $M=2.7$ for the Bugs group, $M=2.1$ for Ariel, $M=2.2$ for the nonautobiographical Disney ad. A $t$-test comparison found the Bugs group to be more confident than the other groups that they had met him, $t(114)=1.67, p=.04$. Participants were also asked whether they remembered specifically shaking hands with Bugs at the park as a child, $16 \%$ in the Bugs condition remembered doing so, compared to $7 \%$ in the Ariel group, and $7 \%$ in the nonautobiographical group. A comparison between the Bugs and other-ad conditions was significant, $16 \%$ versus $7 \%, \chi^{2}(1, N=131)=2.6, p=.05$. In contrast, there was no significant difference between the Ariel-exposed group and other ad conditions on confidence they had met Ariel at the park, $M=$ 1.3 for Ariel, $M=1.8$ for Bugs, $M=1.3$ for nonautobiographical Disney. However, there was a greater tendency for the subjects to believe they had shaken hands with Ariel as a child if they received the false ad: 7\% of those in the Ariel condition remembered shaking her hand compared to $0 \%$ in the Bugs condition, and $4 \%$ in the nonautobiographical Disney condition; a comparison between the Ariel and other-ad groups was significant at $\chi^{2}(1, N=131)=3.49, p=.03$.

\section{Discussion}

The main finding of this experiment is that featuring impossible events in autobiographical advertising can cause people to believe they had experienced the events. For example, $16 \%$ of people claimed that they shook hands with Bugs after receiving the false Bugs ad; 7\% said they remembered meeting Ariel, a character that had not yet been introduced, after seeing an ad suggesting all children meet her at the park. Neither character would have been at the park during the participants' childhood, demonstrating that autobiographical ads can alter memories of the past. As found in Experiment 1, imagination inflation occurred, where people became more confident that the ad-suggested event had happened to them when they were children.

The Bugs ad was more effective in inducing this memory change. This could be because Bugs is a better-known character, and thus easier for participants to imagine during the ad exposure. For instance, in their study of imagining's effect on prediction of future actions, Sherman, Cialdini, Schwartzman, and Reynolds (1985) found that easier-to-imagine illnesses were judged as more likely to occur. Goff and Roediger (1998) found that as the number of imaginings of false experiences in- 
creased, so did the reported memories of participating in these events. Perhaps if participants had received several cues indicating the false characters were associated with Disney, there would be a higher reporting of impossible memories. There is some evidence to suggest this might be the case: There was a relationship observed between confidence in having met Bugs and memory of the shaking-hands experience, which was missing in the Ariel condition. This participant seemed to accept the Bugs ad, despite her initial feeling that it was incorrect:

The first thing that went through my mind when looking at the ad was “why is Bugs Bunny on a Disneyland ad . . . isn't he a Warner Bros. character?" I'm still confused about whether he is or not, but oh well ... .

The advertising may make an event seem more plausible and help consumers develop (or amend) a script for the childhood experience, two factors thought to be important in generating a false memory (Pezdek, Finger, \& Hodge, 1997).

\section{GENERAL DISCUSSION}

The two studies provide empirical evidence for autobiographical advertising's influence on how consumers remember their past. Specifically, it was found that autobiographically focused advertising can make events (even impossible ones) seem more likely to have happened to consumers as children. In Experiment 1 it was found that an autobiographical ad increased consumers' confidence that they had shaken hands with Mickey Mouse in a before-age-10 visit to the park. There was no way to determine whether the ad had activated a true memory or created a new, false one. Experiment 2 found an increase in confidence that participants had experienced the ad-suggested scenario, but, in addition, found them more likely to believe they had met characters at the park who would not have been at Disney during their childhood.

The idea that autobiographical advertising can influence how consumers remember their past is a timely issue. Manufacturers like Ovaltine $^{\mathrm{TM}}$, Alka Seltzer ${ }^{\mathrm{TM}}$, Maxwell House ${ }^{\mathrm{TM}}$, and Shake-n-Bake ${ }^{\mathrm{TM}}$ have begun to dig into their vaults from the 1950 s and 60 s to pull out nostalgic images from past advertising campaigns. Undeniably, such ads tap into some existing consumer memories from their childhood. Marketers had believed the process began and ended with the ads cuing actual past experiences, as Freud's general belief regarding the special status of the original memory has lingered.

But times are changing, and some marketers are beginning to realize that memories are constructive. Some have even benefited from the fact that their consumers' memories have been manufactured. Take, for ex- 
ample, Stewart's root beer. They report many adults seem to remember growing up drinking Stewart's frosty root beer in bottles. This is impossible, because the company only began full-scale distribution 10 years ago, and prior to that only fountain drinks were available. It could be that glass bottles adorned with sayings like "original" "old-fashioned" and "since 1924" provide consumers the illusion of a past that they might have shared as a child. In fact, the vice president of Stewart's marketing swears he remembers drinking their soda after Little League games in an area where distribution was unlikely, but admits, "Memories are always better when they're embellished" (Prince, 2000).

Although there is no direct evidence Disney altered memories through their "Remember the Magic" campaign, the evidence collected here suggests it is at least possible. The power of memory alteration is that consumers are not aware they have been influenced. The feeling associated with remembering a past event, of "seeing" the event unfold in their mind's eye, provides one the belief that how it is recollected is how it happened. Participants held this belief about the permanence of memory; most indicated that the ad had little (or no effect) on their recollections. One participant wrote:

While I was reading it (the Disney ad) I was thinking that I have to take my children there someday because of the great memories that I have from there and probably always will have.

Most people are under the belief that memory is a permanent store and with hypnosis or other special techniques past information can be recovered (Loftus \& Loftus, 1980).

Autobiographical advertising, like hypnosis, allows the consumer to become personally involved in the message. Consumers, for the most part, enjoy the trip back in memory, and the marketer benefits from the positive affect brought forth by their role as memory guide. As a guide, the marketers' message has consequences on what consumers ultimately remember. Those who received the advertising were more confident the childhood experiences suggested in the advertising had happened to them.

Marketers can use autobiographical referencing to re-establish a personal relationship with their consumers. These autobiographical recollections serve important social and personal functions for consumers. For example, one participant wrote:

It brought back memories indeed. I guess I thought the story-beginning was a bit cheesy but then I realize I do have to remember what the experience was like when I was younger. It made you want to run to a Walt Disney Resort, I must admit. It sounds like a lot of fun! The theme "Remember the Magic" I think really caters to all ages, even adults, who may have forgotten what the "magic" was like-take me, for instance! 
Another discussed the social aspects of this remembering process, writing that the ad "reminds them of happy memories and encourages them to share with others." Marketers can benefit on two counts by being the memory guide: directly, by influencing the consumer's attitude and purchase intention, and indirectly, by activating positive word-ofmouth regarding the brand.

Remembering is often a social activity in which people come to some agreement about the past (Hyman et al., 1995) and it is much more likely to take place in the context of friends, family, or advertising than with psychotherapists. In some sense, life is a continual memory alteration experiment where memories continually are shaped by new incoming information (Hyman et al., 1995). This brings forth ethical considerations. Is it all right for marketers to knowingly manipulate consumers' past? On one hand, the alteration will occur whether or not that was the intent of the marketer. And, in most cases, the advertiser is unlikely to try to plant a negative memory, as has been the issue with false memories of childhood abuse. On the other hand, there are ways in which the marketer can enhance the likelihood consumer memories will be consistent with their advertising messages. At the very least, consumers ought to be aware of that power.

Autobiographical referencing is one way to influence consumers' recollections. The ads employed in these studies accomplished that by providing consumers the imagery tools with which to build their memory. According to Reconstructionist theorist Frederic Bartlett (1932), an image becomes the device for picking bits out of schemes (of existing knowledge) and organizing it in such a way that decreases the variability in the reconstruction of the past situation. Typical ad rating scales may not be effective in determining whether an ad will or will not be successful in bringing forth consumer memories. This research found another scale, Wells $R$, to be slightly better in assessing the potential elaborative effects.

\section{LIMITATIONS AND FUTURE RESEARCH}

The subject pool was fairly homogeneous undergraduates. Generations exposed to similar media will become more homogeneous in the types of memories they recall. Different generations may have distinct time posts or markers that should be targeted for the Disney experience, for example, different characters or rides. Holbrook and Schindler (1996) find that there are critical periods for which particular experiences are imprinted and learning and affect are created for the brand or service. Childhood experiences may have been a critical period in the foundation of consumer's knowledge about Disney, though for other product categories different ages might be better suited for memory revision (e.g., 
drinking a particular beer in college). Future research should address which life periods should be targeted in autobiographical ads, depending on consumer age and product category.

The research environment also presents limitations. Participants were instructed to think about the advertising as it was presented to them. Such directed attention might not be representative of actual advertising exposures. Future research might vary the level of advertising exposure to determine how that influences the recollection process.

There are many opportunities for future investigations into this issue of memory alteration. For example, one avenue might look at what type of consumers are most likely to be influenced by autobiographical referencing. Forty-eight percent of the population is susceptible to hypnotic suggestion; these consumers might also be the ones most apt for brand memory distortion. The Disassociated Experience Scale (DES) has been fairly robust in capturing this effect (average $r$ about 0.3 ).

Because Mickey Mouse is a well-known icon of Disney and is probably already a central part of consumer participants' script of visiting the park, the event of shaking hands may have been easier to imagine than with a lesser-known character (Ariel) or an unrelated character (Bugs). Not all participants in Experiment 2 easily accepted the false suggestion, as this participant wrote:

Well first off I notice that Bugs Bunny is a Warner Bros. character rather than Walt Disney so in essence I feel a sense of false advertising here from the Disney company.

Previous work on false memories finds that very similar characters, for example, Mickey Mouse and Minnie, are easily substituted for one another in memory (Loftus, 1997). The participants had only one advertising exposure to associate these newer characters with Disney. It is quite possible that this research underestimates the true effects that autobiographical advertising has on shaping consumers' pasts because in the marketplace consumers may see the ads several times.

\section{REFERENCES}

Ainsworth, M. D. (1985, Spring). Patterns of attachment. Clinical Psychologist, $38,27-29$.

Anderson, S. J., \& Conway, M. A. (1993). Investigating the structure of autobiographical memories. Journal of Experimental Psychology: Learning, Memory, \& Cognition, 19, 1178-1196.

Bartlett, F. C. (1932). Remembering. Cambridge: Cambridge University Press.

Baumgartner, H., Sujan, M., \& Bettman, J. R. (1992). Autobiographical memories, affect and consumer information processing. Journal of Consumer Psychology, 1, 53-82.

Belli, R. F., \& Loftus, E. F. (1996). The pliability of autobiographical memory: 
Misinformation and the false memory problem. In D. C. Rubin (Ed.), Remembering our past: Studies in autobiographical memory (pp. 157-179).

Boller, G. W. (1990). The vicissitudes of product experience: "Songs of our consuming selves" in drama ads. In M. E. Goldberg, G. J. Gorn, \& R. W. Pollay (Eds.), Advances in consumer research (Vol. 17, pp. 621-625).

Braun, K. A. (1999). Postexperience advertising effects on consumer memory. Journal of Consumer Research, 25, 319-334.

Bruner, J. (1986). Actual minds, possible worlds. Cambridge, MA: Harvard University Press.

Garry, M., Manning, C. G., Loftus, E. F., \& Sherman, S. J. (1996). Imagination inflation: Imagining a childhood event inflates confidence that it occurred. Psychonomic Bulletin \& Review, 3, 208-214.

Goff, L. M., \& Roediger, H. L. III. (1998). Imagination inflation for action events: Repeated imaginings lead to illusory recollections. Memory \& Cognition, 26, 20-33.

Haber, R. N., \& Haber, L. (1996). Antecedent conditions and operational definitions for recovered memory effects. Psychonomics Society Convention, Chicago.

Holbrook, M. B., \& Schindler, R. M. (1996). Market segmentation based on age and attitude toward the past: Concepts, methods, and findings concerning nostalgic influences on customer tastes. Journal of Business Research, 37, $27-39$.

Hyman, I. E., Husband, T. H., \& Billings, F. J. (1995). False memories of childhood experiences. Applied Cognitive Psychology, 9, 181-197.

Hyman, I. E., \& Pentland, J. (1996). The role of mental imagery in the creation of false childhood memories. Journal of Memory and Language, 35, 101-117.

Johnson, M. K., Foley, M. A., Suengas, A. F., \& Raye, C. L. (1988). Phenomenal characteristics of memories for perceived and imagined autobiographical events. Journal of Experimental Psychology: General, 117, 371-376.

Krugman, H. E. (1967). The measurement of advertising involvement. Public Opinion Quarterly, 30, 349-356.

Lindsay, D. S., \& Read, J. D. (1994). Psychotherapy and memories of childhood sexual abuse: A cognitive perspective. Applied Cognitive Psychology, 8, 281338.

Loftus, E. F. (1997). Creating false memories. Scientific American, 277(3), 7075.

Loftus, E. F., \& Ketcham, K. (1994). The myth of repressed memory. New York: St. Martin's Press.

Loftus, E. F., \& Loftus, G. R. (1980). On the permanence of stored information in the human brain. American Psychologist, 35, 409-420.

Loftus, E. F., \& Pickrell, J. E. (1995). The formulation of false memories. Psychiatric Annals, 25, 720-725.

Marconi, J. (1996, October 21). Retro marketing helps brands gain new image. Marketing News, 30, p. 10.

Neisser, U., \& Fivush, R. (1994). The remembered self: Construction and accuracy in the self narrative. Cambridge: Cambridge University Press.

Pezdek, K., Finger, K., \& Hodge, D. (1997). Planting false childhood memories: The role of plausibility. Psychological Science, 8, 437-441. 
Prince, G. W. (2000, March 15). Yesterday, today and tomorrow. Beverage Word, pp. 52-54.

Puto, C. P., \& Wells, W. D. (1983). Informational and transformational advertising: The differential effects of time. In T. K. Kinnear (Ed.), Advances in consumer research (Vol. 11, pp. 638-643).

Roese, N. J. (2000). Counterfactual thinking and marketing: Introduction to the special issue. Psychology \& Marketing, 17, 1.

Schacter, D. L. (1995). Memory distortion. Cambridge, MA: Harvard University Press.

Schacter, D. L., Koutstaal, W., Johnson, M. K., \& Gross, M. S. (1997). False recollection induced by photographs: A comparison of older and younger adults. Psychology \& Aging, 12, 203-215.

Schwarz, N. (1996). Cognition and communication. Mahwah, NJ: Lawrence Erlbaum.

Sherman, S. J., Cialdini, R. B., Schwartzman, D. F., \& Reynolds, K. D. (1985). Imagining can heighten or lower the perceived likelihood of contracting a disease: The mediating effect of ease of imagery. Personality \& Social Psychology Bulletin, 11, 118-127.

Spiegel, D. (1997). Memories: True and false. American Psychologist, 52, 995 996.

Sujan, M., Bettman, J. R., \& Baumgartner, H. (1993). Influencing consumer judgments using autobiographical memories: A self-referencing perspective. Journal of Marketing Research, 30, 422-436.

Thompson, C. P., Skowronski, J. J., Larsen, S. F., \& Betz, A. (1996). Autobiographical memory: Remembering what and remembering when. Mahwah, NJ: Lawrence Erlbaum.

Wells, W. D. (1986). Three useful ideas. In R. J. Lutz (Ed.), Advances in Consumer Research (Vol. 13, pp. 9-12). Provo, UT: Association for Consumer Research.

Correspondence regarding this article should be sent to: Kathryn Braun, Marketing Memories ${ }^{\mathrm{TM}}$; P.O. Box 1842, Auburn, AL 36831-1842. 